\title{
The optimum marker for the detection of lymphatic vessels (Review)
}

\author{
LING-LING KONG $^{1 *}$, NIAN-ZHAO YANG ${ }^{1 *}$, LIANG-HUI SHI ${ }^{1}$, GUO-HAI ZHAO ${ }^{1}$, \\ WENBIN ZHOU $^{1,2}$, QIANG DING ${ }^{1,2}$, MING-HAI WANG ${ }^{1}$ and YI-SHENG ZHANG ${ }^{1}$ \\ ${ }^{1}$ Department of General Surgery, The First Affiliated Yijishan Hospital of Wannan Medical College, \\ Wuhu, Anhui 241000; ${ }^{2}$ Department of Breast Surgery, The First Affiliated Hospital \\ of Nanjing Medical University, Nanjing, Jiangsu 210029, P.R. China
}

Received February 22, 2017; Accepted July 22, 2017

DOI: $10.3892 / \mathrm{mco} .2017 .1356$

\begin{abstract}
Podoplanin, lymphatic vessel endothelial hyaluronic acid receptor-1, prospero-related homeobox-1 and vascular endothelial growth factor receptor 3 have been demonstrated to have crucial roles in the development of the lymphatic system and lymphangiogenesis process by combining with their corresponding receptors. Thus, the four markers have been widely used in labelling lymphatic vessels for the detection of lymphangiogenesis and lymphatic vessel invasion. Numerous authors have aimed to identify the roles of these four markers in the lymphatic system and the mechanisms have been partly clarified at the molecular level. The aim of the present review was to comprehensively clarify the characteristics and latent action modes of the four markers in order to determine which is the best one for the detection of lymphangiogenesis and lymphatic vessel invasion.
\end{abstract}

\section{Contents}

1. Introduction

2. D2-40

3. LYVE-1

4. Prox-1

5. VEGFR-3

6. Conclusion

Correspondence to: Dr Ming-Hai Wang or Mr Yi-Sheng Zhang, Department of General Surgery, The First Affiliated Yijishan Hospital of Wannan Medical College, 2 Zheshan Western Road, Wuhu, Anhui 241000, P.R. China

E-mail: wangmh0410@sina.com

E-mail: zhangys0109@hotmail.com

${ }^{*}$ Contributed equally

Key words: D2-40, lymphatic vessel endothelial hyaluronic acid receptor-1, prospero-related homeobox 1, vascular endothelial growth factor receptor 3 , lymphangiogenesis, lymphatic vessel

\section{Introduction}

As part of the circulatory system, lymphatic vessels have particular functions in fluid homeostasis, lipid absorption, immune cell trafficking and causative agent filtration (1). Obviously disparate from blood vessels, the lymphatic endothelial cells are ulteriorly sorted in sub-compartments of the lymphatic vasculature (1-3). The lymphatic vascular system consists of a compact network of blind-ended, slight-walled lymphatic capillaries and collecting lymph vessels that drain exudative protein-rich fluid from the majority of tissues that transport the lymph by way of the thoracic duct to the venous circulation (4). In addition, lymphatic channels have a crucial role in the course of tumor development and metastasis; however, the mechanism of tumor metastasis in the lymphatic pathway remains unclear. Nevertheless, several lymphatic endothelial markers, such as vascular endothelial growth factor receptor 3 (VEGFR-3), lymphatic vessel endothelial hyaluronic acid receptor-1 (LYVE-1), prospero-related homeobox-1 (Prox-1) and podoplanin are widely used in the detection of lymphangiogenesis and lymphatic vessel invasion in a variety of cancer types (5-7). These markers interact with each other in various physiological processes. During murine embryogenesis, the first lymph sacs sprout from the cardinal vein in response to elevating levels of homeobox domain-related transcriptional factor, Prox-1, and the specific receptor of hyaluronan (HA), LYVE-1, around embryonic day 10.5 (E10.5). Meanwhile, the level of lymphatic endothelium specific receptor, VEGFR-3, remains high in lymphatic endothelial cells (LECs), whereas its expression is decreased substantially in vascular endothelial cells $(8,9)$. Specific markers of LEC, VEGFR-3, LYVE-1, Prox-1 and podoplanin, have provided novel insights into the biology of malignant tumors. Other studies have demonstrated the co-expression of podoplanin, VEGFR-3, Prox-1 and LYVE-1 in LECs of normal adult and tumor tissues $(8,10)$. The present review aimed to determine which is the most effective marker for the detection of lymphangiogenesis and lymphatic vessel invasion.

\section{D2-40}

Podoplanin, first identified in rats, is a $43-\mathrm{kDa}$ membrane glycoprotein of podocytes (11). The podoplanin gene is a 
gene with $34.2 \mathrm{~kb}$ and eight exons that is responsible for the synthesis of podoplanin. The plasma membrane is the subcellular location of the encoded protein. Two species of podoplanin mRNA, which most likely stem from alternative splicing, have been verified by northern blotting (12).

Podoplanin is expressed specifically in lymphatic endothelium, and does not exist in the blood vasculature (13). It has a crucial role in preventing cellular adhesion and is involved in regulating the formation of podocyte foot processes and the maintenance of glomerular permeability $(11,14,15)$. Additionally, podoplanin is also expressed in a variety of normal and neoplastic tissues (16-19). Podoplanin has been identified in the development of tooth germ, implicating a role in odontogenesis (20). Furthermore, its expression in various odontogenic tumors implies a role in promoting tumor invasiveness (20-22).

Podoplanin may increase the invasiveness of tumors through its ability to alter actin in the cytoskeleton of tumor cells, contributing to their intensive motility (23). The association between podoplanin and the actin cytoskeleton appears to be mediated by ezrin, whose phosphorylation is notably increased when podoplanin is overexpressed (24-26). Furthermore, podoplanin increases the activity of Rho GTPases, predominantly RhoA, reflecting a different cytoskeletal organization in different cell types (19). Inhibition of RhoA leads to a reduced motility of tumor cells (26).

D2-40 is a selective antibody to podoplanin, based on the recognition of a mixed epitope, whose structure is determined by the polypeptide core together with the O-linked carbohydrate chain (27). Compared with anti-podoplanin, D2-40 is monoclonal and may be utilized immediately, whereas anti-podoplanin requires prior affinity purification in nitrocellulose strips containing recombinant protein (28). Additionally, D2-40 may be used in staining paraffin sections without the requirement of epitope retrieval, while anti-podoplanin requires heat-dependent epitope retrieval (28).

As D2-40 is strongly expressed in the cytoplasm of LECs, it has been widely used as a specific marker in detecting tumor lymphovascular invasion (29). It has been demonstrated that lymphovascular invasion was detected in $13.8-16 \%$ of cases of invasive breast cancer on slides marked with hematoxylin and eosin, and this detection rate increased to $28.5 \%$ when staining for podoplanin was used $(30,31)$. The results of multivariate analyses in various tumors have suggested that the expression of D2-40 was the strongest predictor of axillary lymph node metastasis (30-32). Furthermore, patients with tumors lacking podoplanin-positive vessels have been observed to have a better prognosis (33). A previous study has demonstrated that D2-40-positive lymphovascular invasion (LVI) correlates with younger age, premenopausal status and micro-vessel density, but not with tumor size or nuclear grade (34).

D2-40 appears to be an ideal marker for lymphatic vessels on account of the aforementioned evidence. Nevertheless, it should not be ignored that the myoepithelial cells of normal and benign ducts and lobules of the breast are stained when D2-40 is used to mark lymphatic vessels (29). A study by Rabban and Chen (35) demonstrated that normal breast myoepithelium surrounding solid ductal carcinoma in situ express variable degrees of D2-40, which may be misinterpreted as LVI. Therefore, they concluded that $\mathrm{p} 63$ should be synchronously used to stain myoepithelial cells when it is difficult to distinguish between lymphangiovascular invasion and stromal myoepithelial cells in close relation to neoplastic cells (34).

\section{LYVE-1}

HA, an extracellular matrix glycosaminoglycan, is an indispensable element of skin and mesenchymal tissues that regulates cell migration in the course of wound healing, inflammation and embryonic morphogenesis (36). LYVE-1 is a specific receptor of HA, first identified by Banerji in 1999 (37). It is a member of the Link protein superfamily, with a deduced amino acid sequence of 322 residues, with $41 \%$ similarity to the cluster of differentiation $44 \mathrm{HA}$ receptor (38). However, LYVE-1 integrates with HA on the luminal face of lymph vessels (Fig. 1), and is never present in blood vessels (37).

Interactions between LYVE-1 and the extracellular matrix glycosaminoglycan, HA, may regulate leukocyte migration through the lymphatic vasculature (38). The serum level of LYVE-1 has been identified to be significantly lower in patients with lung cancer with metastasis in comparison with those without (6). It has been suggested that LYVE-1 could be used in predicting cancer progression (6). The interaction between LYVE-1 and HA was identified to be involved in the adhesion of tumor cells to lymphatic vessels (39). Furthermore, by using a novel approach such as reverse transcription-quantitative polymerase chain reaction, it has been demonstrated that the expression of LYVE-1 in breast tissue implies that lymphangiogenesis is occurring in the area (40). Furthermore, the expression of LYVE-1 was higher in breast cancer cases with axillary lymph node metastasis than those without (40). A study by Ramani et al (7) indicated that the upregulation of LYVE-1 may predict a poor prognosis in neuroblastoma. Carcinoma-induced angiogenesis regulated by cyclooxygenase (COX) is controlled via two mechanisms: COX-2 modulates production of angiogenic factors by cancer cells, while COX-1 regulates angiogenesis in endothelial cells (41). Expression of LYVE-1 was demonstrated to be positively correlated with COX-2 or vascular endothelial growth factor-C (VEGF-C) expression in breast cancer tissues (42). Recent research may explain the feasible mechanism of this phenomenon. The membrane type 1-matrix metalloproteinase, an endogenous suppressor of lymphatic vessel growth, directly sheds LYVE-1 on lymphatic endothelial cells to inhibit LYVE-1-mediated lymphangiogenic reactions and suppresses VEGF-C production from pro-lymphangiogenic macrophages through blocking the nuclear factor- $\mathrm{\kappa B}$ signal path to restrain lymphangiogenesis (43).

In order to determine the exact function of LYVE-1 in the development of lymph vasculature, a murine model lacking the LYVE-1 gene has been created. It has been reported that mice lacking the LYVE-1 gene develop properly and establish a functional network of lymphatic vessels and lymph nodes that are thoroughly in accordance with the wild-type mice (44). No disruption occurred in the process of HA metabolism, in the development or differentiation of leukocyte subsets, or in dendritic cell trafficking or tumor growth (44). This lack of an obvious phenotype suggests that LYVE-1 does not have a major structural, developmental or regulatory role and implies 


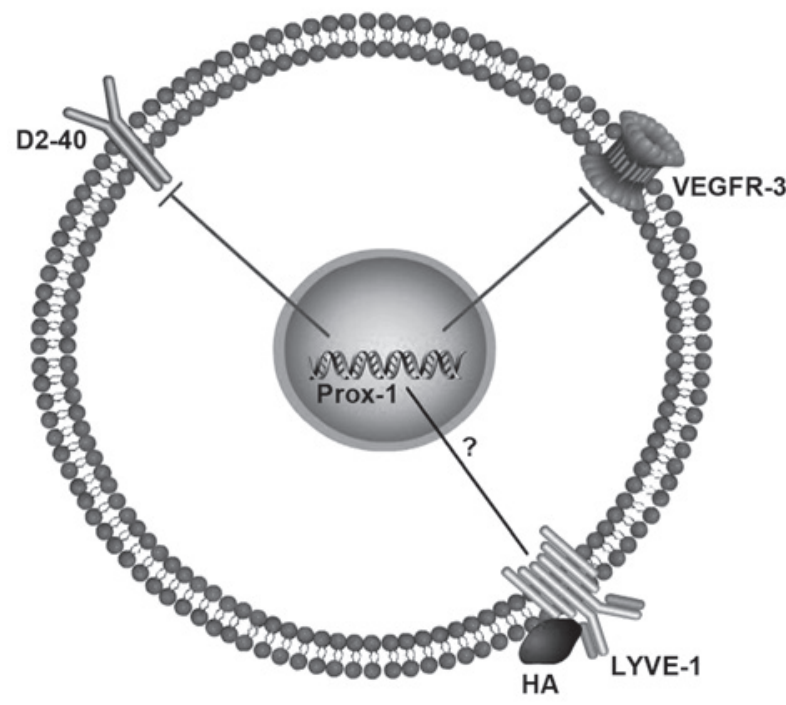

Figure 1. Possible relationship between markers of lymphatic vessels. The aberrant expression of Prox-1 decreases the expression of VEGFR-3 and D2-40. LYVE-1 integrates with HA on the luminal face of the lymph vessel. Prox-1, prospero-related homeobox-1; VEGFR-3, vascular endothelial growth factor receptor 3; LYVE-1, lymphatic vessel endothelial hyaluronic acid receptor-1; ?, currently unclear.

that the lack of LYVE-1 is compensated by an unidentified module or that the role of LYVE-1 is much more specialized than previously imagined (44). Furthermore, true endothelial trans-differentiation vs. non-continuous endothelial-like macrophages (LYVE-1 ${ }^{+}$and stabilin- $1^{+}$) cannot be clarified completely, unless double markers are used in staining LYVE-1 for distinguishing clearly between LYVE-1+ lymphatics and LYVE-1 ${ }^{+}$tumor-infiltrating macrophages (45).

\section{Prox-1}

The homeobox gene, Prox-1, was originally cloned by homology to the Drosophila melanogaster gene, prospero (46). Analysis of the expression pattern of Prox-1 suggested that it performs different functions in a variety of tissues, including the lens, heart, liver, pancreas and central nervous system (46).

It has been demonstrated that inactivation of the Prox-1 gene in mice results in embryonic lethality and phenotypic alterations of the lens and liver (47). A study by Wigle and Oliver (9) indicated that Prox-1 has an important function during the early formation of the lymph sacs by endothelial venous budding, and likely later during lymphatic growth by endothelial sprouting from these primary lymph sacs. Prox-1 appears to function in a time-dependent manner, following the formation of the lymphatic vasculature in each individual embryonic structure (9). It was also demonstrated that Prox-1 merely had a role in the development of the lymphatic but not the blood vascular system (9). At a similar time, a study by Hong et al (48) indicated that Prox-1 regulated the procedure of vascular phenotype conversion into a lymphatic phenotype. Its activity is sufficient to override the blood vasculature phenotype in primary human dermal microvascular endothelial cells by promoting a lymphatic endothelial phenotype instead (47).

Other research has demonstrated that the viability of Prox-1 in a conservative subpopulation of embryonic vein endothelial cells is crucial not only to promote lymphangiogenesis but also to determine a lymphatic fate (8). Prox-1 activates transcription of a key cell cycle regulatory gene by blocking it from binding to DNA, and regulates lymphatic endothelial cell proliferation (49). In 2008, Dadras et al (50) discovered that Prox 1 may be related to a more aggressive vascular tumor phenotype with partial lymphatic differentiation, with characteristics of Kaposi's sarcoma. Following this, Prox-1 was indicated to be correlated with the pathogenesis of oral Kaposi's sarcoma, as there is a gradual increase in the number of positive spindle cells from patch/plaque to nodular stages (51). Therefore, Prox-1 may be used as a novel diagnostic biomarker to discriminate between oral Kaposi's sarcoma and benign oral vascular lesions (51).

\section{VEGFR-3}

VEGFR-3 (also denoted Flt4) is a protein compound of $195 \mathrm{kDa}$. The compound is primarily cleaved in the fifth immunoglobulin (Ig)-like domain, producing an N-terminal peptide, which remains attached to the original protein via a disulfide bond (52). VEGFR-3 is sensitized through binding with VEGF-C and VEGF-D (53). Proteolytic processing of VEGF-C and VEGF-D results in increased affinity for binding to both VEGFR-2 and VEGFR-3 (54,55). It is easier for VEGF-C to combine with VEGFR-3 than to VEGFR-2 (56). VEGF-C binding requires Ig-loops 1 and 2 in VEGFR-3 (57), while binding to VEGFR-2 requires loops 2 and 3 (58). Human VEGF-D demonstrates analogical affinity for both VEGFR-2 and VEGFR-3, conversely, murine VEGF-D integrates only with VEGFR-3 (59). Furthermore, N-terminal residues in VEGF-D are a prerequisite for the activation of VEGFR-3, but not VEGFR-2 (60).

A study by Kaipainen et al (61) demonstrated that the expression of VEGFR-3 is restricted to lymphatic vessels during murine development. Also, VEGFR-3 is specifically expressed in lymphatic vessels by cloning the human fms-like tyrosine kinase (FLT) 4 gene, in human adult tissues (62). Knockout of the VEGFR-3 gene leads to defectiveness of blood vessel development only in the early embryonic period of mice, which implies that VEGFR-3 has a vital role in the formation of the embryonic cardiovascular system before the emergence of lymphatic vessels (63). VEGFR-3 is also expressed weakly in capillary endothelium of normal breast tissue, but expressed strongly in intraductal carcinomas (53).

In an experimental model with VEGF-D-expressing tumors, administration of VEGF-D monoclonal antibody reduced the growth of primary tumors and the rate of lymph node metastases $(64,65)$. A similar result was obtained with anti-VEGFR-3; however, no effect was observed on the development of lung metastasis (66). Other studies have indicated that both VEGF-C and VEGF-D, which are ligands for VEGFR-3, may promote tumor lymphangiogenesis and lymphatic metastasis (64,67-69). Furthermore, VEGFR-3 has been reported to stimulate the proliferation of angiogenic blood vessel endothelium in breast cancer (53).

Therapeutic agents that block VEGF signaling have been developed with the aim of retarding angiogenesis in diseases involved in tissue growth and inflammation, such as cancer. Sunitinib, an oral multiple-receptor tyrosine kinase inhibitor, 
has been authorized to be used in different types of solid tumors and targets VEGF receptors, stem cell factor receptor, platelet-derived growth factor receptor and FLT3 (70). It has been demonstrated to be biochemically active against urothelial carcinoma cells in vitro and in vivo (71,72).

Furthermore, there are many other kinds of biomarkers, such as 5 '-nucleotidase, the second lymphatic chemokines, desmoplakin and $\beta$-chemotactic factor D6, that may be used in the detection of lymphatic vasculature (73-75). However, these markers have not been widely used in tumor lymph vessel examination due to the lack of reliability.

\section{Conclusion}

The aforementioned markers bind to their own specific binding site in different modes. They all function in diverse ways at different stages of growth and development. At E9.5-E10.0, LYVE-1 is expressed uniformly in the endothelial cells of the cardinal vein, whereas Prox-1 is only able to be detected in a rigorous subpopulation of endothelial cells around this stage (8). These markers may also regulate each other in unclarified ways. The aberrant expression of Prox-1 in differentiated blood vessel endothelial cells leads to lymphatic endothelial regrouping, which is associated with increasing blood vascular-specific gene expression and the decreased expression of a large number of lymphatic-specific genes, such as VEGFR-3 and D2-40 $(48,76)$. However, the intrinsic mechanism remains unclear. Not all of these markers are detected in all cancer types. For instance, LYVE-1 cannot be detected in MDA-MB-231 breast cancer cells (40). Therefore, it is essential that the combined application of lymphatic endothelium markers is used to detect lymphatic vessels for improving the sensitivity and veracity of detection.

\section{Acknowledgements}

The present study was supported by grants from the National Science Foundation of China (grant no. 81372828) and The First Affiliated Yijishan Hospital with Wannan Medical College Introduce Talents of Scientific Research Fund Project (grant no. YR201305).

\section{References}

1. Schulte-Merker S, Sabine A and Petrova TV: Lymphatic vascular morphogenesis in development, physiology and disease. J Cell Biol 193: 607-618, 2011.

2. Tammela T and Alitalo K: Lymphangiogenesis: Molecular mechanisms and future promise. Cell 140: 460-476, 2010.

3. Kazenwadel J and Harvey NL: Morphogenesis of the lymphatic vasculature: A focus on new progenitors and cellular mechanisms important for constructing lymphatic vessels. Dev Dyn 245 209-219, 2016.

4. WitteMH,BernasMJ,MartinCPandWitte CL:Lymphangiogenesis and lymphangiodysplasia: From molecular to clinical lymphology. Microsc Res Tech 55: 122-145, 2001.

5. Cunnick GH, Jiang WG, Douglas-Jones T, Watkins G, Gomez KF, Morgan MJ, Subramanian A, Mokbel K and Mansel RE: Lymphangiogenesis and lymph node metastasis in breast cancer. Mol Cancer 7: 23, 2008.

6. Nunomiya K, Shibata Y, Abe S, Inoue S, Igarashi A, Yamauchi K, Kimura T, Aida Y, Nemoto T, Sato M, et al: Relationship between serum level of lymphatic vessel endothelial hyaluronan receptor- 1 and prognosis in patients with lung cancer. J Cancer 5 . 242-247, 2014.
7. Ramani P, Dungwa JV and May MT: LYVE-1 upregulation and lymphatic invasion correlate with adverse prognostic factors and lymph node metastasis in neuroblastoma. Virchows Arch 460: 183-191, 2012.

8. Wigle JT, Harvey N, Detmar M, Lagutina I, Grosveld G, Gunn MD, Jackson DG and Oliver G: An essential role for Prox 1 in the induction of the lymphatic endothelial cell phenotype. EMBO J 21: 1505-1513, 2002.

9. Wigle JT and Oliver G: Prox1 function is required for the development of the murine lymphatic system. Cell 98: 769-778, 1999.

10. Weninger W, Partanen TA, Breiteneder-Geleff S, Mayer C, Kowalski H, Mildner M, Pammer J, Stürzl M, Kerjaschki D, Alitalo $\mathrm{K}$ and Tschachler E: Expression of vascular endothelial growth factor receptor-3 and podoplanin suggests a lymphatic endothelial cell origin of Kaposi's sarcoma tumor cells. Lab Invest 79: 243-251, 1999.

11. Breiteneder-Geleff S, Matsui K, Soleiman A, Meraner P, Poczewski H, Kalt R, Schaffner G and Kerjaschki D: Podoplanin, novel 43-kd membrane protein of glomerular epithelial cells, is down-regulated in puromycin nephrosis. Am J Pathol 151: 1141-1152, 1997.

12. Kriehuber E, Breiteneder-Geleff S, Groeger M, Soleiman A, Schoppmann SF, Stingl G, Kerjaschki D and Maurer D: Isolation and characterization of dermal lymphatic and blood endothelial cells reveal stable and functionally specialized cell lineages. J Exp Med 194: 797-808, 2001.

13. Breiteneder-Geleff S, Soleiman A, Kowalski H, Horvat R, Amann G, Kriehuber E, Diem K, Weninger W, Tschachler E, Alitalo K and Kerjaschki D: Angiosarcomas express mixed endothelial phenotypes of blood and lymphatic capillaries: Podoplanin as a specific marker for lymphatic endothelium. Am J Pathol 154: 385-394, 1999.

14. Schmid H, Henger A, Cohen CD, Frach K, Gröne HJ, Schlöndorff D and Kretzler M: Gene expression profiles of podocyte-associated molecules as diagnostic markers in acquired proteinuric diseases. J Am Soc Nephrol 14: 2958-2966, 2003.

15. Levidiotis V and Power DA: New insights into the molecular biology of the glomerular filtration barrier and associated disease. Nephrology (Carlton) 10: 157-166, 2005.

16. Kanner WA, Galgano MT and Atkins KA: Podoplanin expression in basal and myoepithelial cells: Utility and potential pitfalls. Appl Immunohistochem Mol Morphol 18: 226-230, 2010.

17. Martín-Villar E, Scholl FG, Gamallo C, Yurrita MM, Muñoz-Guerra M, Cruces J and Quintanilla M: Characterization of human PA2.26 antigen (T1alpha-2, podoplanin), a small membrane mucin induced in oral squamous cell carcinomas. Int J Cancer 113: 899-910, 2005.

18. Kato Y, Kaneko M, Sata M, Fujita N, Tsuruo T and Osawa M: Enhanced expression of Aggrus (T1alpha/podoplanin), a platelet-aggregation-inducing factor in lung squamous cell carcinoma. Tumour Biol 26: 195-200, 2005.

19. Schacht V, Dadras SS, Johnson LA, Jackson DG, Hong YK and Detmar M: Up-regulation of the lymphatic marker podoplanin, a mucin-type transmembrane glycoprotein, in human squamous cell carcinomas and germ cell tumors. Am J Pathol 166: 913-921, 2005.

20. Zustin J, Scheuer HA and Friedrich RE: Podoplanin expression in human tooth germ tissues and cystic odontogenic lesions: An immunohistochemical study. J Oral Pathol Med 39: 115-120, 2010.

21. Kikuchi K, Ito S, Inoue H, González-Alva P, Miyazaki Y, Sakashita H, Yoshino A, Katayama Y, Terui T, Ide F and Kusama K: Immunohistochemical expression of podoplanin in so-called hard $\alpha$-keratin-expressing tumors, including calcifying cystic odontogenic tumor, craniopharyngioma and pilomatrixoma. J Oral Sci 54: 165-175, 2012.

22. Tsuneki M, Maruyama S, Yamazaki M, Cheng J and Saku T: Podoplanin expression profiles characteristic of odontogenic tumor-specific tissue architectures. Pathol Res Pract 208: 140-146, 2012.

23. Moustakas A and Heldin $\mathrm{CH}$ : Signaling networks guiding epithelial-mesenchymal transitions during embryogenesis and cancer progression. Cancer Sci 98: 1512-1520, 2007.

24. Scholl FG, Gamallo C, Vilaró S and Quintanilla M: Identification of PA2.26 antigen as a novel cell-surface mucin-type glycoprotein that induces plasma membrane extensions and increased motility in keratinocytes. J Cell Sci 112: 4601-4613, 1999.

25. Wicki A, Lehembre F, Wick N, Hantusch B, Kerjaschki D and Christofori G: Tumor invasion in the absence of epithelial-mesenchymal transition: Podoplanin-mediated remodeling of the actin cytoskeleton. Cancer cell 9: 261-272, 2006. 
26. Martín-Villar E, Megías D, Castel S, Yurrita MM, Vilaró S and Quintanilla M: Podoplanin binds ERM proteins to activate RhoA and promote epithelial-mesenchymal transition. J Cell Sci 119: 4541-4553, 2006.

27. Marks A, Sutherland DR, Bailey D, Iglesias J, Law J, Lei M, Yeger H, Banerjee D and Baumal R: Characterization and distribution of an oncofetal antigen (M2A antigen) expressed on testicular germ cell tumours. Br J Cancer 80: 569-578, 1999.

28. Kahn HJ and Marks A: A new monoclonal antibody, D2-40, for detection of lymphatic invasion in primary tumors. Lab Invest 82: 1255-1257, 2002.

29. Ren S, Abuel-Haija M, Khurana JS and Zhang X: D2-40: An additional marker for myoepithelial cells of breast and the precaution in interpreting tumor lymphovascular invasion. Int J Clin Exp Pathol 4: 175-182, 2011.

30. Braun M, Flucke U, Debald M, Walgenbach-Bruenagel G, Walgenbach KJ, Höller T, Pölcher M, Wolfgarten M, Sauerwald A, Keyver-Paik M, et al: Detection of lymphovascular invasion in early breast cancer by D2-40 (podoplanin): A clinically useful predictor for axillary lymph node metastases. Breast Cancer Res Treat 112: 503-511, 2008.

31. El-Gendi S and Abdel-Hadi M: Lymphatic vessel density as prognostic factor in breast carcinoma: Relation to clinicopathologic parameters. J Egypt Natl Canc Inst 21: 139-149, 2009.

32. Birner P, Schindl M, Obermair A, Breitenecker G, Kowalski H and Oberhuber G: Lymphatic microvessel density as a novel prognostic factor in early-stage invasive cervical cancer. Int J Cancer 95: 29-33, 2001.

33. Niemiec JA, Adamczyk A, Ambicka A, Mucha-Malecka A, Wysocki WM and Ryś J: Distribution of podoplanin-positive tumor vessels predicts disease-specific survival of node-positive breast cancer patients treated with anthracyclines and/or taxanes. Cancer Invest 32: 168-177, 2014.

34. Tezuka K, Onoda N, Takashima T, Takagaki K, Ishikawa T, Wakasa T, Wakasa K and Hirakawa K: Prognostic significance of lymphovascular invasion diagnosed by lymphatic endothelium immunostaining in breast cancer patients. Oncol Rep 17: 997-1003, 2007.

35. Rabban JT and Chen YY: D2-40 expression by breast myoepithelium: Potential pitfalls in distinguishing intralymphatic carcinoma from in situ carcinoma. Hum Pathol 39: 175-183, 2008.

36. Laurent TC and Fraser JR: Hyaluronan. FASEB J 6: 2397-2404, 1992.

37. Banerji S, Ni J, Wang SX, Clasper S, Su J, Tammi R, Jones M and Jackson DG: LYVE-1, a new homologue of the CD44 glycoprotein, is a lymph-specific receptor for hyaluronan. J Cell Biol 144: 789-801, 1999.

38. Jackson DG, Prevo R, Clasper S and Banerji S: LYVE-1, the lymphatic system and tumor lymphangiogenesis. Trends Immunol 22: 317-321, 2001.

39. Du Y,Liu Y, Wang Y,He Y, Yang C and Gao F: LYVE-1 enhances the adhesion of HS-578T cells to COS-7 cells via hyaluronan. Clin Invest Med 34: E45-E54, 2011

40. Cunnick GH, Jiang WG, Gomez KF and Mansel RE: Lymphangiogenesis quantification using quantitative PCR and breast cancer as a model. Biochem Biophys Res Commun 288 1043-1046, 2001

41. Tsujii M, Kawano S, Tsuji S, Sawaoka H, Hori M and DuBois RN: Cyclooxygenase regulates angiogenesis induced by colon cancer cells. Cell 93: 705-716, 1998

42. Timoshenko AV, Chakraborty C, Wagner GF and Lala PK: COX-2-mediated stimulation of the lymphangiogenic factor VEGF-C in human breast cancer. Br J Cancer 94: 1154-1163, 2006.

43. Wong HL, Jin G, Cao R, Zhang S, Cao Y and Zhou Z: MT1-MMP sheds LYVE-1 on lymphatic endothelial cells and suppresses VEGF-C production to inhibit lymphangiogenesis. Nat Commun 7: 10824, 2016

44. Gale NW, Prevo R, Espinosa J, Ferguson DJ, Dominguez MG, Yancopoulos GD, Thurston G and Jackson DG: Normal lymphatic development and function in mice deficient for the lymphatic hyaluronan receptor LYVE-1. Mol Cell Biol 27: 595-604, 2007.

45. Schledzewski K, Falkowski M, Moldenhauer G, Metharom P, Kzhyshkowska J, Ganss R, Demory A, Falkowska-Hansen B, Kurzen H, Ugurel S, et al: Lymphatic endothelium-specific hyaluronan receptor LYVE-1 is expressed by stabilin-1+, F4/80+, $\mathrm{CD} 11 \mathrm{~b}+$ macrophages in malignant tumours and wound healing tissue in vivo and in bone marrow cultures in vitro: Implications for the assessment of lymphangiogenesis. J Pathol 209: 67-77, 2006 .
46. Oliver G, Sosa-Pineda B, Geisendorf S, Spana EP, Doe CQ and Gruss P: Prox 1, a prospero-related homeobox gene expressed during mouse development. Mech Dev 44: 3-16, 1993.

47. Wigle JT, Chowdhury K, Gruss P and Oliver G: Prox 1 function is crucial for mouse lens-fibre elongation. Nat Genet 21: 318-322, 1999.

48. Hong YK, Harvey N, Noh YH, Schacht V, Hirakawa S, Detmar M and Oliver G: Prox1 is a master control gene in the program specifying lymphatic endothelial cell fate. Dev Dyn 225: 351-357, 2002.

49. Baxter SA, Cheung DY, Bocangel P, Kim HK, Herbert K, Douville JM, Jangamreddy JR, Zhang S, Eisenstat DD and Wigle JT: Regulation of the lymphatic endothelial cell cycle by the PROX1 homeodomain protein. Biochim Biophys Acta 1813: 201-212, 2011.

50. Dadras SS, Skrzypek A, Nguyen L, Shin JW, Schulz MM, Arbiser J, Mihm MC and Detmar M: Prox-1 promotes invasion of kaposiform hemangioendotheliomas. J Invest Dermatol 128: 2798-2806, 2008.

51. Benevenuto de Andrade BA, Ramírez-Amador V, Anaya-Saavedra G, Martínez-Mata G, Fonseca FP, Graner E and Paes de Almeida O: Expression of PROX-1 in oral Kaposi's sarcoma spindle cells. J Oral Pathol Med 43: 132-136, 2014.

52. Pajusola K, Aprelikova O, Armstrong E, Morris S and Alitalo K: Two human FLT4 receptor tyrosine kinase isoforms with distinct carboxy terminal tails are produced by alternative processing of primary transcripts. Oncogene 8: 2931-2937, 1993

53. Valtola R, Salven P, Heikkilä P, Taipale J, Joensuu H, Rehn M, Pihlajaniemi T, Weich H, deWaal R and Alitalo K: VEGFR-3 and its ligand VEGF-C are associated with angiogenesis in breast cancer. Am J Pathol 154: 1381-1390, 1999.

54. Joukov V, Sorsa T, Kumar V, Jeltsch M, Claesson-Welsh L, Cao Y, Saksela O, Kalkkinen N and Alitalo K: Proteolytic processing regulates receptor specificity and activity of VEGF-C. EMBO J 16: 3898-3911, 1997.

55. Stacker SA, Stenvers K, Caesar C, Vitali A, Domagala T, Nice E, Roufail S, Simpson RJ, Moritz R, Karpanen T, et al: Biosynthesis of vascular endothelial growth factor-D involves proteolytic processing which generates non-covalent homodimers. J Biol Chem 274: 32127-32136, 1999.

56. Mäkinen T, Veikkola T, Mustjoki S, Karpanen T, Catimel B, Nice EC, Wise L, Mercer A, Kowalski H, Kerjaschki D, et al: Isolated lymphatic endothelial cells transduce growth, survival and migratory signals via the VEGF-C/D receptor VEGFR-3. EMBO J 20: 4762-4773, 2001.

57. Jeltsch M, Karpanen T, Strandin T, Aho K, Lankinen H and Alitalo K: Vascular endothelial growth factor (VEGF)/VEGF-C mosaic molecules reveal specificity determinants and feature novel receptor binding patterns. J Biol Chem 281: 12187-12195, 2006.

58. Leppänen VM, Prota AE, Jeltsch M, Anisimov A, Kalkkinen N, Strandin T, Lankinen H, Goldman A, Ballmer-Hofer K and Alitalo K: Structural determinants of growth factor binding and specificity by VEGF receptor 2. Proc Natl Acad Sci USA 107: 2425-2430, 2010

59. Baldwin ME, Catimel B, Nice EC, Roufail S, Hall NE, Stenvers KL, Karkkainen MJ, Alitalo K, Stacker SA and Achen MG: The specificity of receptor binding by vascular endothelial growth factor-d is different in mouse and man. J Biol Chem 276: 19166-19171, 2001.

60. Leppänen VM, Jeltsch M, Anisimov A, Tvorogov D, Aho K, Kalkkinen N, Toivanen P, Ylä-Herttuala S, Ballmer-Hofer K and Alitalo K: Structural determinants of vascular endothelial growth factor-D receptor binding and specificity. Blood 117: $1507-1515,2011$

61. Kaipainen A, Korhonen J, Mustonen T, van Hinsbergh VW, Fang GH, Dumont D, Breitman M and Alitalo K: Expression of the fms-like tyrosine kinase 4 gene becomes restricted to lymphatic endothelium during development. Proc Natl Acad Sci USA 92: 3566-3570, 1995.

62. Pajusola K, Aprelikova O, Korhonen J, Kaipainen A, Pertovaara L, Alitalo R and Alitalo K: FLT4 receptor tyrosine kinase contains seven immunoglobulin-like loops and is expressed in multiple human tissues and cell lines. Cancer Res 52: 5738-5743, 1992.

63. Dumont DJ, Jussila L, Taipale J, Lymboussaki A, Mustonen T, Pajusola K, Breitman M and Alitalo K: Cardiovascular failure in mouse embryos deficient in VEGF receptor-3. Science 282: 946-949, 1998

64. Stacker SA, Caesar C, Baldwin ME, Thornton GE, Williams RA, Prevo R, Jackson DG, Nishikawa S, Kubo H and Achen MG: VEGF-D promotes the metastatic spread of tumor cells via the lymphatics. Nat Med 7: 186-191, 2001. 
65. Jain RK and Padera TP: Prevention and treatment of lymphatic metastasis by antilymphangiogenic therapy. J Natl Cancer Inst 94: 785-787, 2002.

66. He Y, Kozaki K, Karpanen T, Koshikawa K, Yla-Herttuala S, Takahashi T and Alitalo K: Suppression of tumor lymphangiogenesis and lymph node metastasis by blocking vascular endothelial growth factor receptor 3 signaling. J Natl Cancer Inst 94: 819-825, 2002.

67. Mäkinen T, Jussila L, Veikkola T, Karpanen T, Kettunen MI, Pulkkanen KJ, Kauppinen R, Jackson DG, Kubo H, Nishikawa $\mathrm{S}$, et al: Inhibition of lymphangiogenesis with resulting lymphedema in transgenic mice expressing soluble VEGF receptor-3. Nat Med 7: 199-205, 2001.

68. Mandriota SJ, Jussila L, Jeltsch M, Compagni A, Baetens D, Prevo R, Banerji S, Huarte J, Montesano R, Jackson DG, et al: Vascular endothelial growth factor-C-mediated lymphangiogenesis promotes tumour metastasis. EMBO J 20: 672-682, 2001.

69. Skobe M,Hawighorst T, Jackson DG, Prevo R, Janes L, Velasco P, Riccardi L, Alitalo K, Claffey K and Detmar M: Induction of tumor lymphangiogenesis by VEGF-C promotes breast cancer metastasis. Nat Med 7: 192-198, 2001.

70. Takahashi S: Vascular endothelial growth factor (VEGF), VEGF receptors and their inhibitors for antiangiogenic tumor therapy. Biol Pharm Bull 34: 1785-1788, 2011.
71. Beekman KW, Bradley D and Hussain M: New molecular targets and novel agents in the treatment of advanced urothelial cancer. Semin Oncol 34: 154-164, 2007.

72. Sonpavde G, Jian W, Liu H, Wu MF, Shen SS and Lerner SP: Sunitinib malate is active against human urothelial carcinoma and enhances the activity of cisplatin in a preclinical model. Urol Oncol 27: 391-399, 2009.

73. Rudert M and Tillmann B: Detection of lymph and blood vessels in the human intervertebral disc by histochemical and immunohistochemical methods. Ann Anat 175: 237-242, 1993.

74. Kucera R, Topolcan O, Treskova I, Kinkorova J, Windrichova J, Fuchsova R, Svobodova S, Treska V, Babuska V, Novak J and Smejkal J: Evaluation of IL-2, IL-6, IL-8 and IL-10 in Malignant Melanoma Diagnostics. Anticancer Res 35: 3537-3541, 2015.

75. Harada T, Shinohara M, Nakamura S, Shimada M and Oka M Immunohistochemical detection of desmosomes in oral squamous cell carcinomas: Correlation with differentiation, mode of invasion, and metastatic potential. Int J Oral Maxillofac Surg 21: 346-349, 1992

76. Petrova TV, Mäkinen T, Mäkelä TP, Saarela J, Virtanen I, Ferrell RE, Finegold DN, Kerjaschki D, Ylä-Herttuala S and Alitalo K: Lymphatic endothelial reprogramming of vascular endothelial cells by the Prox-1 homeobox transcription factor. EMBO J 21: 4593-4599, 2002. 